ARTIGOS

\title{
O lugar dos pertencimentos do escritor-adulto na reconstrução das memórias de infância
}

\section{The effects of the adult-writer's identity and belongingness on the reconstruction of childhood memories}

Ana Maria de Oliveira Galvão ${ }^{(i)}$

Larissa Maria de Resende Neiva (ii)

Mônica Yumi Jinzenji (iii)

\begin{abstract}
(i) Universidade Federal de Minas Gerais, Belo Horizonte, MG, Brasil. https://orcid.org/0000-00019063-8267. anamariadeogalvao@gmail.com

(ii) Prefeitura de Belo Horizonte, MG, Brasil. larysmary@hotmail.com

(iii) Universidade Federal de Minas Gerais, Belo Horizonte, MG, Brasil. myjinzenji@gmail.com
\end{abstract}

Resumo: O artigo analisa os efeitos de diferentes pertencimentos do escritoradulto na reconstrução de suas memórias de infância. Utiliza como fontes principais seis autobiografias escritas por filhos de pais analfabetos ou com baixa escolaridade, nascidos na primeira metade do século XX, quatro deles em Minas Gerais, Brasil, e dois em Illinois, Estados Unidos. Verificou-se que os autores, ao considerarem a autobiografia como ensinamento, buscam estratégias para se legitimarem como exemplos de superação. $\mathrm{Na}$ escrita, elegem um pertencimento, como o socioeconômico e/ou o étnico-racial, como eixo para situar o lugar de onde falam, tornando-o o fio condutor das narrativas e da releitura de suas infâncias e trajetórias de vida.

Palavras-chave: autobiografias, história da cultura escrita, história da infância 


\section{pro.posições}

\section{$e$-ISSN 1980-6248}

Abstract: This article analyzes the effects of the adult-writer's identity and belongingness on the reconstruction of their childhood memories. The research's main sources are six autobiographies written by children of parents who are either illiterate or have a low level of education. All the writers were born in the first half of the twentieth century, four of them in Minas Gerais, Brazil, and the other two in Illinois, United States. It was found that, considering the autobiography as a learning tool, the authors seek strategies to show themselves as examples of successful life stories. When writing their autobiographies, the authors choose an aspect of their identity and belongingness, be it socio-economic or ethnic-racial, as the basis for their narrative, and make it the place from which to recreate their childhood stories and life trajectories.

Keywords: autobiographies, history of written culture, bistory of childhood

\section{Introdução}

Este artigo tem como objetivo compreender os efeitos de diferentes pertencimentos ${ }^{1}$ - socioeconômico, étnico-raciais, religiosos, profissionais, de gênero e de origem geográfica do escritor-adulto na reconstrução de suas memórias de infância.

Como fontes principais de análise, foram utilizadas seis autobiografias ${ }^{2}$, escritas por indivíduos filhos de pais analfabetos ou com baixa escolaridade, ou seja, pertencentes à primeira geração de letrados ${ }^{3}$ em suas linhagens familiares, sendo quatro nascidos na primeira metade do século XX em Minas Gerais, Brasil, e os outros dois em Illinois, Estados Unidos ${ }^{4}$. As obras foram publicadas na segunda metade do século XX, por pequenas editoras e/ou por

\footnotetext{
1 Pertencimento é compreendido, neste artigo, como um processo resultante das negociações entre o indivíduo/grupo e as fronteiras materiais e simbólicas que configuram o mundo social (Ennes \& Marcon, 2014).

2 Trabalhamos exclusivamente com livros publicados entre 1963 e 2007, em formato impresso. Nas pesquisas que deram origem a este artigo, analisamos um corpus mais amplo de obras - aproximadamente 30. As autobiografias analisadas neste texto foram: Cofre de lembranças: uma trabalhadora rural do Jequitinhonha conta sua história (Gomes, 1997); Diário de Bitita (Jesus, 1986); Les Brownlee: the autobiography of a pioneering African-American journalist (Les Brownlee, 2007); Memórias de um carpinteiro (Santos, 1963); Vá com Deus, mãe (Souza, 2004); I refuse to learn to fail (Travis, 1992).

3 Trata-se, portanto, de indivíduos, na expressão de Bourdieu e Passeron (1964), que não herdaram capital cultural das gerações familiares passadas.

${ }^{4}$ Em virtude do espaço de que dispomos neste artigo, não explicitaremos os pressupostos que guiaram a realização da pesquisa nos dois países, baseados no que se vem convencionando denominar "histórias cruzadas" (Barros, 2014). Destacamos apenas que não realizamos um "estudo comparado", mas buscamos analisar, na operação historiográfica, os casos investigados a partir de alguns "procedimentos relacionais", como é próprio dessa tendência. Trata-se, para usar uma expressão de Certeau (1982), de uma "experimentação", em que buscamos, considerando as especificidades de cada contexto histórico analisado, apreender elementos comuns que caracterizam a escrita autobiográfica de "novos letrados".
} 


\section{pro.posıções}

$e$-ISSN 1980-6248

http://dx.doi.org/10.1590/1980-6248-2016-0064

edições do autor ${ }^{5}$. Foram utilizados, ainda, dados secundários, como estatísticas sobre taxas de alfabetização e de escolarização, acerca dos locais onde nasceram e viveram os sujeitos.

Embora as autobiografias sejam fontes privilegiadas para o campo de estudos sobre história da infância, é preciso discutir as suas especificidades, sob o risco de considerar as narrativas reconstruídas pelo escritor-adulto retratos do que viveram. Assim como a grande maioria das fontes utilizadas em estudos que tratam da infância na perspectiva histórica, a autobiografia nos possibilita elaborar versões sobre a infância a partir do ponto de vista dos adultos. Segundo Moysés Kuhlmann (1998), “a história da criança é uma história sobre a criança [a ênfase no original]" (p.31). A infância, como etapa da vida, se materializa de múltiplas formas nos diversos contextos sociais, históricos e geográficos e deixa poucos rastros "puros", diretos. Além da historicidade da infância, que nos possibilita pensar nos múltiplos significados para essa etapa da vida ao longo da história e para os diversos contextos culturais, é importante considerar a coexistência de vários tipos de representações e práticas "no seio de uma mesma sociedade, uma prevalecendo sobre a outra em determinado momento por motivos culturais e sociais que nem sempre é fácil distinguir" (Gélis, 1993, p. $328)$.

No caso das autobiografias, a "apreensão" dessa fase da vida é inevitavelmente mediada pelo adulto que textualiza a reconstrução da própria vivência infantil (Gullestad, 2005). Trata-se, portanto, de um duplo processo de mediação, primeiramente operado pelo crivo da memória (considerando-se também, por exemplo, a censura e a autocensura, e o endereçamento) e, em seguida, pelo processo de produção textual (que também é interpelado, entre outros fatores, pelo tipo de relação que se tem com a escrita, e pelas condições de publicação).

Nesse tipo de narrativa, o autor busca dar coerência ao que, a princípio, são fatos (re)construídos, simultaneamente, sob a névoa da lembrança e do esquecimento. O sujeito que escreve busca construir uma imagem de si que corresponda àquela que ele quer que seja a sua própria identidade, em um processo que Bourdieu (1996) denominou de "ilusão biográfica". Nessa textualização ${ }^{6}$, omite voluntária e/ou involuntariamente, através da escrita, fatos que

\footnotetext{
${ }^{5}$ A exceção é o livro Diário de Bitita, de Carolina de Jesus, publicado por uma grande editora, a Nova Fronteira. ${ }^{6}$ Nesse sentido, o narrador distingue-se do autor empírico, pois pode ser considerado, na expressão de Umberto Eco (2008), um tipo de estratégia textual.
} 


\section{pro.posıções}

http://dx.doi.org/10.1590/1980-6248-2016-0064

$e$-ISSN 1980-6248

não correspondem ao que ele quer ser (e se torna); dá sentidos edificantes ${ }^{7}$ a episódios banais; romanceia o cotidiano que, por si só, é rotineiro e tedioso. Além disso, o processo de produção da memória autobiográfica é guiado pelo presente: é a partir do lugar que ocupa no momento da escrita que o autor do relato autobiográfico seleciona aquilo que comporá sua história, sua identidade, de modo que o princípio tenha relação com o que será o fim. A memória é seletiva, e esse processo se torna ainda mais agudo na maturidade, quando a maioria das obras analisadas neste trabalho foi escrita. Assim, na narrativa o(a) autor(a) enfatiza sua vida pessoal e, em particular, os processos de construção da sua (suposta) identidade. É necessário, portanto, considerar que a infância retratada no texto autobiográfico, ao mesmo tempo em que exprime, em alguns aspectos, a realidade social, também a constrói. Devemos considerar que é o adulto, autor da autobiografia que, cronológica e afetivamente distante das vivências infantis, reconstrói essa fase da vida, atualizando-a conforme os pertencimentos sociais que o atravessam. Ao se constituírem em um relato retrospectivo (Lejeune, 2014), as autobiografias nos permitem pensar em como a produção sobre a infância é resultado de um trabalho da memória, mediado por diversos fatores, vinculados predominantemente ao presente. Elas nos permitem, portanto, operar em dois tempos: o tempo vivido e o tempo em que o vivido é transformado em narrado.

\section{A autobiografia como “ensinamento” da superação}

No caso do tipo de autobiografia analisado neste artigo, escrito por pessoas comuns e com uma intimidade construída com a leitura e a escrita ao longo de suas trajetórias - e não herdada -, algumas especificidades desse gênero parecem se tornar ainda mais agudas. Embora seja típico do relato autobiográfico, como afirma Alberti (1991), (in)formar, aconselhar e ensinar o leitor, por meio da difusão e da exemplificação de uma experiência singular, nas autobiografias analisadas, essa característica parece se sobrepor às demais e guiar o pacto autobiográfico (Lejeune, 2014) estabelecido entre novos letrados e leitores: a vida do(a) autor(a) é um exemplo que merece ser contado; desse modo, os outros podem aprender com ela.

\footnotetext{
7 Utilizamos, aqui, o adjetivo "edificante" em alguns dos sentidos a ele atribuídos em dicionários contemporâneos: "que edifica moralmente; edificativo; edificador; moralizador. ... Instrutivo, esclarecedor". Deriva, portant0, do verbo edificar: “induzir à virtude ... infundir sentimentos morais e religiosos" (Ferreira, 1988, p.234).
} 


\section{pro.posıções}

http://dx.doi.org/10.1590/1980-6248-2016-0064

$e$-ISSN 1980-6248

A pesquisa mostrou, de modo geral, que os textos analisados podem ser considerados como narrativas edificantes, organizadas a partir de histórias de superação. Os autores das autobiografias parecem partilhar da ideia de que o ato de escrever é motivado, antes de tudo, pelo desejo de mostrar como pessoas comuns são capazes de superar uma infância difícil e ser, em diferentes aspectos, bem-sucedidas. Em outras palavras, são histórias de resiliência e assim devem ser compreendidas por seus leitores.

Que táticas os autores utilizam para mostrar ao leitor que sua vida "merece um livro"? A busca de opinião e comentários de outras pessoas, preferencialmente daquelas social e simbolicamente legitimadas, parece ser recurso usado frequentemente pelos novos letrados (Galvão, 2006) para provar ao possível leitor que sua vida merece se tornar uma autobiografia. Os prefácios e as introduções contribuem, nesse sentido, para construir esse lugar exemplar que os autores desejam ocupar. Embora a "apresentação" e a "promoção" do livro sejam propósitos comunicativos típicos dos gêneros introdutórios (Bezerra, 2006), parece-nos que, nas autobiografias de novos letrados, as estratégias discursivas utilizadas pelos prefaciadores se concentram primordialmente na vida do autor e, secundariamente, na obra.

Na autobiografia de Les Brownlee ${ }^{8}$ (2007), John Kass, apresentado como colunista do jornal Chicago Tribune, afirma que os capítulos do livro podem inspirar muitas famílias, ao narrar a história de um jovem, sozinho, “desesperado" (Kass, 2007, p.7) para aprender, ler e entender. Relembra que o autor perdeu o pai para o racismo ${ }^{9}$, passou momentos difíceis na infância e na adolescência, mas, mesmo assim, tornou-se jornalista e professor e, nessa última atividade, também dava suporte aos seus alunos.

$\mathrm{Na}$ autobiografia de Travis $(1992)^{10}$, o médico que escreve o Prefácio afirma que o autor faz, no livro, um trabalho singular de ensinar pelo exemplo, ao mostrar atitudes e valores

\footnotetext{
${ }^{8} \mathrm{O}$ autor nasceu em 1915 em Rhode Island, mas cresceu e viveu a maior parte da vida em Evanston, subúrbio de Chicago. Tornou-se um dos primeiros jornalistas negros da região de Chicago. Neto de escravos do sul dos Estados Unidos, seu pai, que era dono de um pequeno negócio e pastor, morreu quando ele tinha 7 anos. Sua mãe era empregada doméstica. Racismo, segregação e discriminação marcaram sua escolarização e a vida na cidade. A autobiografia de Les Browlee foi concluída, quando ele estava no hospital com câncer, e publicada depois de sua morte, em 2005, por sua última esposa, Priscilla Ruth MacDougall.

${ }^{9} \mathrm{O}$ pai de Les Brownlee morreu aos 46 anos, de apendicite. Por ser negro, teve assistência negada no hospital de Evanston e, em virtude do atraso no tratamento, morreu, depois de ser transferido para o hospital de Chicago.

${ }^{10}$ Dempsey Travis nasceu em 1920 e morreu em 2009 em Chicago. Tornou-se um empresário de sucesso na área de negócios imobiliários. Nos anos 60, lutou, junto com outros líderes dos direitos civis, pela dessegregação do mercado imobiliário. Escreveu, além da autobiografia, seis livros, todos sobre aspectos da vida dos afro-
} 


\section{pro.posições}

$e$-ISSN 1980-6248

de que todos precisam para melhorar o país. Reafirma que, a despeito das influências negativas presentes na vida do autobiografado, como as condições precárias de habitação, de trabalho e o racismo sofrido ao longo de sua trajetória, ele "done well and succeeded" (Bell, 1992, p.7) ${ }^{11}$. Conclui, então, que o livro de Travis deveria ser lido por todos os afro-americanos que gostariam de ter sucesso ou de compreender o sucesso (p.2) ${ }^{12}$. O prefaciador afirma, ainda, que as histórias narradas na obra indicam que os jovens afro-americanos devem ser ensinados a atribuir o seu sucesso à sua habilidade, e os seus fracassos à sua falta de esforço. No mesmo sentido se inscreve a Introdução do livro, escrita por outra pessoa reconhecida por sua legitimidade social e simbólica ${ }^{13}$ : nela, Harvette Grey destaca que a história de como Travis se recusou a aprender a fracassar mostra que não se pode permitir que o fracasso se torne o epitáfio da comunidade afro-americana (Grey, 1992).

Assim como nas autobiografias norte-americanas, autores de obras brasileiras também se reportam a terceiros na busca de credibilidade. Os prefácios e as apresentações das obras de Carolina de Jesus ${ }^{14}$, de Zelita Gomes ${ }^{15}$ e de Luiz Gonzaga dos Santos ${ }^{16}$ são escritos por pessoas de destaque social e simbólico, que ajudam a delinear a ideia de que se trata de vidas "que merecem ser narradas", além de reforçar os pertencimentos a partir dos quais as narrativas são construídas. Em Diário de Bitita, o Prefácio, escrito por um membro da

americanos. Sua infância girou em torno do trabalho. Seu pai era um trabalhador manual, não especializado, de um grande frigorífico de Chicago. Sua mãe era dona de casa.

11 "Fez bem feito e foi bem sucedido".

12 "Dr. Bell is the Executive Director of the Community Mental Health Council in Chicago, Illinois" (Travis, 1992, p.8). [Dr. Bell é o Diretor Executivo do Conselho Comunitário de Saúde Mental em Chicago, Illinois].

13 PhD. "Clinical Psychologist, University of Illinois at Chicago" (Travis, 1992, p.11). PPsicólogo Clínico, Universidade de Illinois, em Chicago].

${ }^{14}$ Carolina de Jesus nasceu em 1914, em Sacramento, Minas Gerais, e morreu em 1977. Foi empregada doméstica e catadora de lixo. Além de Diário de Bitita, escreveu outros três livros, entre os quais Quarto de Despejo: diário de uma favelada, publicado em 1960 e traduzido em diversos países. Ela nunca conheceu o pai e declara, no livro, que a mãe, que era cozinheira, empregada doméstica e babá, não sabia nem ler nem escrever. Teve uma infância marcada por muitas dificuldades. Na vida adulta, encontrou na escrita um meio de dar sentido à dura vida experienciada. Comenta, no livro, de forma abundante, as condições de vida do negro no Brasil, denunciando o preconceito e a desigualdade raciais no País.

15 Zelita Gomes nasceu na zona rural no Vale do Jequitinhonha, em 1945. Seu pai era trabalhador rural e professor leigo, embora nunca tivesse frequentado a escola. A autora se autodenomina trabalhadora rural, embora também tenha atuado como professora leiga. Foi membro de movimentos sociais vinculados à Igreja Católica e a partidos políticos.

${ }^{16}$ Luiz Gonzaga dos Santos, descendente de escravos, nasceu em 1898, em Filadélfia (atual Téofilo Otoni). Seu pai era carpinteiro e sua mãe dona de casa. Também se tornou carpinteiro. 


\section{pro.posıções}

$e$-ISSN 1980-6248

Academia de Letras do Triângulo Mineiro, o Prof. Dimas da Cruz Oliveira (1986), também contribui para a construção da ideia de que se trata de uma vida exemplar:

O "Diário de Bitita" representa o testemunho dramático de uma vida marcada pela luta contra o preconceito e a injustiça, uma vida que se destacou apesar de todos os fatores adversos. Neste livro, da escritora sacramentana Carolina Maria de Jesus, encontramos alguém que jamais desistiu de seus ideais, que jamais desacreditou das potencialidades do ser humano, apesar de tudo. (p. 5)

Já o Prefácio da obra Cofre de lembranças foi redigido pelo Professor de Antropologia da Universidade Federal de Minas Gerais, Pierre Sanchis (1997), enquanto a Apresentação foi escrita por Carlos Figueiredo, Professor de Psicologia da mesma universidade. Ao se referir a Zelita Gomes, o prefaciador apresenta-a como uma mulher que "está lutando contra a ameaça do vazio - vazio de gente emigrada. E por isso mesmo, procura desesperadamente, há algum tempo, expressar-se com marca própria no cenário cultural e social do país" (p.6). O exemplo da vida da narrada não se encontra, como analisaremos em outro momento, na singularidade de uma trajetória marcada pelo mérito individual, mas na potencialidade que ela representa para um movimento coletivo. Ao se negar a se submeter à exploração de classe, Zelita torna-se um arquétipo da transformação social: "É a história desta decisão, do corte que estabelece numa vida, de seus desdobramentos, pessoais e, sobretudo, coletivos, que este livro revela ao leitor" (p.7).

$\mathrm{Na}$ própria narrativa construída, terceiros são evocados para legitimar certas características que são incorporadas pelo(a) autor(a) narrador(a) adulto(a) como constituintes de sua própria personalidade. Essas supostas características "naturais" do sujeito o levariam a se tornar exemplos de vida. É o que acontece, por exemplo, quando Carolina de Jesus (2007) menciona a fala de pessoas com quem conviveu e que parecem ter tido um papel importante no modo como passou a se perceber como criança e na forma como acabou construindo uma imagem de si: "menina de opinião", "inteligente" (p. 9) e "correta" (p. 35).

Mesmo quando os próprios autobiografados se autoapresentam, tendem a afirmar que são exemplos para seus possíveis leitores. No livro de Vicente de Souza ${ }^{17}$ (2004), o autor

\footnotetext{
$\overline{17}$ Vicente de Souza nasceu em 1935, na zona rural de Boa Esperança. Seus pais, trabalhadores rurais, morreram quando ele era criança, e ele, então, passou a morar com a madrinha, que vivia em boas condições econômicas, na sede da cidade. Na família adotiva, fazia pequenos serviços domésticos e também fora de casa. Aos 25 anos
} 


\section{pro.posıções}

$e$-ISSN 1980-6248

http://dx.doi.org/10.1590/1980-6248-2016-0064

afirma que a leitura da obra pode "incutir no leitor que passa por dificuldades, a ideia de que sempre deve haver esperança de melhores dias" (p. 6).

Como pode ser observado, a releitura que os autores das autobiografias fazem da infância é mediada por múltiplas "vozes" 18 , que se conjugam no momento da escrita, para que provoquem no leitor a sensação de que aquela vida é um exemplo de superação que merece ser narrado em um livro. Essas múltiplas "vozes" são, no entanto, unificadas na narrativa. Entre os recursos utilizados para a construção dessa unificação encontra-se a escolha, pelos autores, de um (ou mais) pertencimento identitário, que se torna o eixo da narrativa e confere sentido e coesão às vidas narradas. Compreendemos que essa escolha, embora possua elementos "concretos" que a sustentem, possui um caráter processual e dinâmico e é, ao mesmo tempo, situacional. A construção do sentimento de pertença se dá em meio a disputas sociais e políticas (Ennes \& Marcon, 2014) que, como veremos, não eram compreendidas desse modo na infância vivida, mas foram elaboradas no momento da escrita como forma de situar a trajetória no conjunto das interações sociais estabelecidas. A ideia de superação dos obstáculos enfrentados durante uma infância marcada por dificuldades é construída, portanto, em cada autobiografia analisada, a partir de certos marcos, vinculados aos diferentes pertencimentos identitários elaborados pelos autores.

\section{Os pertencimentos do escritor-adulto como eixo das narrativas autobiográficas}

As memórias de infância são, portanto, produzidas a partir de eixos escolhidos pelos autores para dar sentido e coerência às suas vidas. Nesse processo, o engajamento em torno de causas relacionadas aos pertencimentos analisados torna-se, em muitos casos, o argumento central sobre o qual se articulam os demais aspectos das trajetórias narradas. Elegemos, para análise neste artigo, dois pertencimentos em que é possível visualizar, muito nitidamente, esse processo: os pertencimentos étnico-racial e socioeconômico.

cursou direito na UFMG, custeou seus estudos e despesas dando aula particular. Foi bancário, promotor e, posteriormente, juiz.

18 Utilizamos a expressão "vozes" no sentido que lhe confere Bakhtin (1997). 


\section{pro.posıções}

http://dx.doi.org/10.1590/1980-6248-2016-0064

\section{$e$-ISSN 1980-6248}

\subsection{O pertencimento étnico-racial}

Alguns autores analisados articulam suas narrativas em torno do eixo do pertencimento étnico-racial. Esse é o caso, particularmente, dos dois autores norteamericanos, Les Brownlee e Dempsey Travis, e de uma escritora brasileira, a mineira Carolina de Jesus. Na obra desses autores, os episódios da infância narrada são produzidos, reinterpretados e ressignificados a partir da ideia de que eles são, antes de tudo, negros. As dificuldades e os obstáculos enfrentados ganham sentido a partir desse lugar de onde escolheram falar. As possibilidades de superá-los, por sua vez, embora também vinculadas ao pertencimento, ora são atribuídas ao mérito individual, ora ao engajamento em causas coletivas. A análise da autobiografia de Les Brownlee (2007), por exemplo, mostra que o fato de ter se tornado um dos primeiros jornalistas afro-americanos da região de Chicago, como indica o subtítulo do livro, foi escolhido para conduzir a narrativa e conferir sentido e coesão a toda sua trajetória. Em Diário de Bitita, as memórias de infância de Carolina de Jesus (2007) são fortemente assinaladas por referências à sua condição de negra e pobre. Grande parte da narrativa se volta para situações vivenciadas pela autora em decorrência desses pertencimentos que em diversos momentos aparecem relacionados. Na obra há, inclusive, capítulos destinados a esses temas, como aqueles intitulados "Os negros" (p. 76), e "Os pobres" (p. 28). O eixo central da narrativa, contudo, se faz a partir de seu pertencimento étnico-racial, uma vez que a autora estabelece como principal elemento para a constituição de sua personalidade, os conflitos e os questionamentos das condições a que se via submetida pelo fato de ser negra.

O fato fundador escolhido por Les Brownlee (2007) para reconstruir a sua infância, marcada por dificuldades, foi a morte do seu pai, em decorrência de ter tido assistência médica negada, pelo fato de ser negro. A partir de então, teve de ajudar sua mãe e suas irmãs mais velhas na subsistência da família. Depois da morte do pai, sua mãe e irmãs, que antes cozinhavam por encomenda, começaram a trabalhar em casas de famílias brancas, como empregadas. De acordo com o autor, elas faziam parte do "corpo negro" e predominantemente feminino que cozinhava, limpava, lavava e passava nas melhores casas para pagar o aluguel e as contas do supermercado.

No caso de Travis (1992), dois episódios ocorridos na infância, em particular, são por ele selecionados para conferir sentido ao que viria a constituir o relato de sua vida. O primeiro, escolhido para iniciar o livro, funciona como um mito de origem. Quando ele foi 


\section{pro.posıções}

$e$-ISSN 1980-6248

http://dx.doi.org/10.1590/1980-6248-2016-0064

ridicularizado por seus vizinhos brancos e contou o episódio à sua mãe, ela tomou um pedaço de veludo preto, o fez tocar no tecido e explicou-lhe que era "soff" ["suave"], "pretty" ["bonito"] (p.22) e o material mais caro do mundo. A seguir, chamou-o de "my black velvet" [“meu veludo negro"] (p.22). A partir desse episódio, o menino-narrador-adulto passou, pelo menos em sua narrativa retrospectiva, a compreender a negritude de um modo positivo e a "recusar-se a aprender a fracassar" (p.23) diante das barreiras raciais e de outros obstáculos que enfrentou na vida. Para ele, a aceitação de autoimagens negativas sobre o pertencimento étnico-racial é que levaria ao fracasso. O segundo episódio foi escolhido para concluir o livro e também funciona como um mito fundador para explicar aquilo que ele se tornaria - "a selfmade multimillionaire" (p. 9), como explicitado na Introdução: quando tinha 6 anos de idade, sonhou que havia se tornado rico e, por isso, o pai não precisaria mais acordar de madrugada para trabalhar. Ao narrar o sonho ao pai, foi alertado, de modo irônico, de que aquele tipo de pensamento, comum a muitas pessoas, era, na verdade, uma ilusão. Para o menino-adulto, aquelas palavras do pai se converteram em um desafio. Naquele momento, prometeu a si mesmo que, por meio de árduo trabalho, conseguiria tornar-se aquilo que havia sonhado. Nos dois episódios narrados, que, não por acaso, abrem e fecham o livro, conjugam-se, simultaneamente, as dificuldades inerentes à sua condição de negro e pobre e, ao mesmo tempo, a possibilidade de, pelo esforço e pelo mérito individuais, serem superadas as dificuldades.

Os obstáculos enfrentados na infância estão relacionados, sobretudo, a dois espaços: a escola e a cidade. Em episódios relativos ao seu processo de escolarização, Les Brownlee (2007) evidencia o racismo, a segregação e a discriminação sofridos, levando o leitor a compreender que o fato de as taxas de escolarização serem relativamente altas nos Estados Unidos nesse período não significava que houvesse igualdade na educação oferecida ${ }^{19}$. Mesmo em Illinois, estado onde a segregação racial era mais frágil do que no sul do país, havia, claramente, escolas para brancos e escolas para negros, com expectativas diferentes para cada grupo. Quando Les Brownlee (2007) alcança uma excelente performance no Binet-Stanford Achievement Test toma conhecimento das ideias do superintendente do distrito, que explicita que aos negros eram mais apropriadas as profissões manuais e, aos brancos, as profissões

\footnotetext{
${ }^{19}$ Em 1920, nos Estados Unidos, a taxa de escolarização entre a população de 5 a 20 anos era de 65,7\% entre os brancos e de $53,5 \%$ entre os negros e demais grupos étnicos. No mesmo ano, a taxa de analfabetismo era de $4 \%$ entre os brancos e de $23 \%$ entre os negros e os outros grupos (United States, 1993).
} 


\section{pro.posıções}

$e$-ISSN 1980-6248

liberais. Essa situação teria lhe provocado, pelo menos no momento de reconstruí-la por meio da escrita - cerca de meio século depois -, extrema revolta. Diversos outros episódios são narrados pelo autor na mesma direção: estudantes negros não podiam participar de certas atividades extracurriculares nem ocupar posições de liderança; não eram incentivados a ter amizades com colegas brancos; e eram acusados injustamente de roubos e outros problemas que eventualmente ocorriam nas escolas. Travis (1992) também relata diversos episódios em que sofreu discriminação de colegas e também de professores em escolas racialmente dessegregadas.

No caso brasileiro, Carolina de Jesus (2007) também apresenta, em sua narrativa, uma infância na escola marcada por preconceitos e humilhações. Em um dos episódios narrados, afirma que estava revoltada com os colegas por terem exclamado, quando ela entrou na sala de aula: “- Que negrinha feia! ... Que olhos grandes, parece sapo!” (p.149). Nas memórias da narradora-adulta, ainda criança ela observava que, para os negros, a vida era mais difícil porque não tinham instrução - "A maioria dos negros era analfabeta" ${ }^{20}$ (p.30). Quando conseguiam algum trabalho, era "exaustivo" (p.66).

O espaço urbano do mesmo modo se mostrava extremante segregado racialmente, no caso norte-americano, não apenas em Chicago, mas também em seus subúrbios, onde Les Brownlee (2007) viveu a maior parte da sua infância. Tensões raciais estavam permanentemente presentes na rotina da cidade, e problemas com a polícia eram constantes, mesmo quando não havia razões aparentes para que ocorressem. No caso de Travis (1992), o próprio bairro, somente de brancos onde, ainda muito novo, foi morar, o fez perceber a segregação espacial urbana. Em sua narrativa, atribui a esse fato a opção que fez, quando adulto, de atuar no ramo imobiliário, onde se tornou militante da causa da habitação dos negros. No caso brasileiro, a segregação espacial era menos explícita, mas Carolina de Jesus (2007) narra diversos episódios de racismo vivenciados quando criança no espaço urbano, fazendo menção à divisão entre "pretos e brancos" no que se refere às atividades realizadas, aos lugares frequentados e às condições de vida em geral. Nas memórias da escritora-adulta,

\footnotetext{
${ }^{20}$ Os índices de analfabetismo em Sacramento, cidade onde a autora nasceu e passou sua infância, eram de $64,2 \%$ em 1920 (Brazil, 1920). O analfabetismo era, portanto, mais generalizado do que a narrativa de Carolina de Jesus dá a ver. Em 1980, na cidade de São Paulo, no entanto, período próximo ao que provavelmente escreve Diário de Bitita, os índices de analfabetismo eram de apenas 17,9\% (Brasil, 1982). Vê-se, portanto, mais uma vez, o fundamental papel ocupado pelo presente do escritor-adulto na invenção de suas memórias de infância.
} 


\section{pro.posıções}

$e$-ISSN 1980-6248

http://dx.doi.org/10.1590/1980-6248-2016-0064

ainda criança "notava ... que nas festas dos negros os brancos não iam" (p.25). Observava, ainda, que "quando o negro envelhecia ia pedir esmola" (p.30). Em suas lembranças, seu cotidiano era marcado por xingamentos e insultos racistas: "Dona Cota, espanca esta negrinha! Que menina cacete! Macaca!" (p.12).

Certamente, o engajamento de quem escreve, ocorrido posteriormente à infância, em causas relacionadas ao pertencimento étnico-racial contribuiu para que essa condição identitária se tornasse o eixo sobre o qual gira a narrativa sobre sua vida. Les Brownlee (2007) participou, ainda na universidade, do Youth Committee Against War [Comitê da Juventude Contra a Guerra], onde conduzia um programa de rádio - que o levava a fazer palestras sobre o tema em diversas escolas - em que falava sobre "paz e preconceito": tensões raciais, segregação e discriminação eram pautas constantes. Já adulto, fez parte da criação da Evanston Urban League, por meio da qual apoiou um candidato a vereador negro, e de vários movimentos contra a segregação e a discriminação raciais na cidade. $\mathrm{Na}$ idade adulta, Travis (1992) também se engajou em várias organizações sociais e políticas que lutavam pelos direitos civis dos afro-americanos, principalmente no que se referia ao ainda segregado mercado imobiliário, instância de sua atuação profissional. Foi um dos líderes da marcha pelos direitos civis de Chicago e, em sua autobiografia, publicou fotos suas com Luther King. No caso de Carolina Maria de Jesus, Diário de Bitita foi escrito alguns anos depois do lançamento do bestseller Quarto de despejo (pela Livraria Francisco Alves, em 1960), quando foi "descoberta" pelo jornalista Audálio Dantas. Após a publicação desse primeiro livro, traduzido em diversos idiomas, Carolina apareceu frequentemente na mídia e via-se constantemente convocada a falar sobre pobreza, racismo e preconceito contra a mulher. Esse engajamento da autora certamente explica a recorrência desses temas no livro analisado no presente trabalho.

A superação dos obstáculos, embora também se relacione ao pertencimento étnicoracial, é atribuída, sobretudo, ao mérito individual, principalmente nas autobiografias norteamericanas analisadas. $\mathrm{Na}$ argumentação tecida, o pertencimento comparece para valorizar, ainda mais, o esforço do personagem, diante de circunstâncias adversas, por ele determinadas: é como se o(a) autobiografado(a) desejasse expressar para seus possíveis leitores que ele(a) superou os obstáculos porque era diferente dos demais negros. $\mathrm{Na}$ autobiografia de Les Brownlee (2007), a ideia de superação - como se pode ver na primeira frase do tópico 


\section{pro.posıções}

$e$-ISSN 1980-6248

"Professor Emeritus", no último capítulo, "How much can a poor boy take?21 " (p.183) - é seguida pela ideia de pioneirismo: "In terms of health care and many other things, doors were still closed as if we were slaves. During my life, I never set out to open any doors, but managed to break down some of those barriers anyway $" 22$ (p.17). Episódios e fatos que mostram que o esforço e o mérito individuais foram decisivos na construção de um lugar social diferente são reiteradamente narrados ao longo do livro, como o fato de ter concluído a high school ${ }^{23}$ em $16^{\circ}$ ou $17^{\circ}$ lugar (entre 521 alunos) e ter sempre recebido notas altas durante sua trajetória de escolarização. No caso de Travis (1992), o mérito individual funciona como um motor para explicar a superação dos sucessivos obstáculos encontrados em sua vida desde o início da narrativa e ganha força em alguns episódios, como naquele em que narra como superou o analfabetismo funcional: como "mágica", um "milagre" aconteceu, pois descobriu que havia conseguido escrever oito páginas em menos de uma hora, em um texto argumentativo. É interessante observar que a meritocracia e o discurso da supervalorização do indivíduo, particularmente forte na história norte-americana, definem o tom desses textos. Em alguns momentos, eles parecem ignorar que, na maioria das vezes, circunstâncias vinculadas a pertencimentos sociais, étnico-raciais e de gênero definem e limitam, por vezes de modo rígido, as ações individuais. ${ }^{24}$

\subsection{O pertencimento socioeconômico}

Outros autores, por sua vez, elegem o pertencimento socioeconômico como aquele que confere sentido às suas vidas narradas e explica, em última análise, por que se tornaram as pessoas que os leitores passam a conhecer por meio da autobiografia. Esses são os casos de três autores brasileiros: Vicente de Souza, Luiz Gonzaga dos Santos e Zelita Gomes.

\footnotetext{
21 "Até onde pode ir um menino pobre?"

22 "Em termos de assistência à saúde e muitas outras coisas, as portas ainda estavam fechadas como se fôssemos escravos. Durante a minha vida, nunca tive a intenção de abrir portas, mas, de todo modo, consegui quebrar muitas dessas barreiras".

23 Equivalente ao atual ensino médio brasileiro.

${ }^{24}$ Em certos casos, nas autobiografias analisadas, as histórias de superação tornam-se histórias coletivas, como no seguinte trecho de Travis (1992), quando se refere à luta pelos direitos civis dos afro-americanos: "These strong willed Black men and women gloried in their roots and shared a common determination to refuse to learn to fail. Some of their contributions are told in this addition to my autobiographical series in the hope that their giant steps will not be lost like footprints in the sand but will lead us to understand how positive influences in our formative years can shape and motivate us to rise above the crowd' (p.14). Esses homens e mulheres negros, fortes e obstinados, vangloriam-se de suas raízes e compartilharam uma determinação comum de se recusarem a aprender a fracassar. Algumas de suas contribuições são contadas e se somam à minha série de autobiografias, na esperança de que seus passos de gigantes não serão perdidos como pegadas na areia, mas nos levarão a compreender como influências positivas nos nossos anos de formação podem nos moldar e motivar a subir acima da multidão.
} 


\section{pro.posıções \\ $e$-ISSN 1980-6248}

http://dx.doi.org/10.1590/1980-6248-2016-0064

A infância é construída por Vicente de Souza (2004) a partir da situação de pobreza extrema que vivenciou na zona rural de Boa Esperança. Vivendo nas propriedades rurais nas quais o pai e os irmãos mais velhos trabalhavam, as condições de vida beiravam a indigência, segundo o autor. As habitações não tinham mais do que quatro cômodos, eram taperas com cobertura de sapê e chão batido. As necessidades fisiológicas eram feitas no chão, em buracos abertos para isso, e a água potável tinha de ser recolhida a mais de $1 \mathrm{~km}$ de distância, em uma "bica". O pai morreu vítima de um acidente relacionado ao trabalho na roça, quando Vicente, caçula de oito irmãos, tinha três meses de vida. Os irmãos mais velhos continuaram a se ocupar dos trabalhos da roça, mas as condições de vida nunca se alteraram: não conseguiam o suficiente para comprar alimentos, roupas e calçados. Sua mãe recebia doações de famílias e de comerciantes que forneciam restos de comida ou mantimentos. A mãe faleceu quando Vicente tinha 8 anos. A impossibilidade de conciliar as atividades da roça com os cuidados da casa fez com que os irmãos decidissem por entregar Vicente para ser criado pela madrinha de batismo que morava na cidade, Dona Chicota, que ele e os irmãos só conheciam pelo nome. A partir desse ponto-chave da narrativa, a miséria é associada à orfandade, e esses dois elementos são responsáveis pela "mudança radical" pela qual vai passar - e ao que atribui o grande "trauma" que o marcará até a idade adulta: a separação de sua família biológica. O falecimento da mãe é apresentado, assim, como o início de seu estranhamento no/do mundo, mas também como o ponto de partida para as mudanças que o levariam aos sucessos profissional e pessoal que atingiu. Não por acaso, o título da sua autobiografia é exatamente Vá com Deus, mãe. A separação da família biológica e a sua adoção por uma família de boas condições financeiras são o marco que, segundo o autor, dá origem ao homem que se tornou: de Vicente, um "capiau da roça" sem registro nem sobrenome, que nunca havia usado um calçado nos pés, para Vicente da Chicota, ou Vicente Figueiredo, sobrenome emprestado informalmente da madrinha, ao ser matriculado no grupo escolar aos 9 anos de idade. Vicente (2004) relata com ênfase como essa mudança foi contrastante: "passei a viver numa das mais elegantes residências da principal praça da cidade” (p. 73), passando a ter novas experiências, a se adaptar aos "costumes da cidade", como brincar com outras crianças e ler gibis. Era também vítima de chacota por parte dos meninos "da cidade", que zombavam de seu ar desajeitado, vestindo calçados e sobretudo. Vicente atribui à pobreza extrema em que viveu durante a infância e à separação de sua família biológica, as características mais marcantes de sua personalidade, como timidez, introversão e insegurança, principalmente no início das 


\section{pro.posıções \\ $e$-ISSN 1980-6248}

http://dx.doi.org/10.1590/1980-6248-2016-0064

atividades na promotoria e na magistratura, carreiras que seguiu na idade adulta até sua aposentadoria. Em suas palavras, a promotoria exigia uma "combatividade que eu não possuía. Era extremamente tímido" devido aos "traumas de infância" (p.169). Nesse sentido, podemos afirmar que há uma tendência a reconstruir uma infância mais precarizada e sofrida do que a vivida. Em vários trechos, por exemplo, o autor interrompe a narrativa com reflexões do presente, evidenciando a visão do adulto sobre a própria infância. Ao se referir à morte da mãe e à decisão dos irmãos mais velhos de entregá-lo para ser criado pela madrinha, acontecimento repetido como o mais traumático da infância e responsável por muito sofrimento, afirma: "não sei se a decisão me chocou nem sei dizer se cheguei a chorar, pois não tinha ideia de uma separação" (p.21). Vê-se, nitidamente, como os episódios vividos na infância, vinculados ao seu pertencimento socioeconômico, funcionam, na narrativa, como uma espécie de motor que passou a determinar toda a sua trajetória de vida.

No caso de Luiz Gonzaga dos Santos (1963), o próprio título da obra, Memórias de um carpinteiro, sugere que seu pertencimento socioprofissional é o condutor da narrativa. $\mathrm{Na}$ verdade, o enfoque dado às memórias parece recair sobre a cidade e sua história, seus personagens e rituais locais, embora o autor procure reunir capítulos sobre a infância e a mocidade, e relatar cronologicamente as sucessivas migrações que realizou em busca de trabalho. A sua origem étnico-racial também aparece como uma importante referência para a construção da sua narrativa, embora busque apagá-la, em diversos momentos do texto. Se, por um lado, o autor afirma ser "descendente de negros africanos e índios da mata de Filadélfia, conforme diziam meus pais, e estes eram meus bisavós, todos escravos e negros” (p.54), por outro insiste em afirmar que, em Diamantina, "não havia muito preconceito de cor" e que, desde a infância, nele "nunca existiu" "o menor complexo de inferioridade" (p.54). Nas festas narradas, entretanto, em muitos momentos o autor se refere à presença de demarcações muito nítidas dos lugares destinados aos negros e aos brancos. Em outras palavras, embora Luiz pudesse eleger o pertencimento étnico-racial como fio condutor de sua narrativa, opta por não fazê-lo. Podemos hipotetizar que, se houvesse se tornado um militante de movimentos relacionados à causa negra no Brasil, certamente daria uma outra intepretação aos eventos que narra sobre sua infância. Teria mesmo, possivelmente, eleito outros episódios para narrar ou se detido com mais detalhes em alguns deles. A sua infância teria sido, portanto, outra embora fosse, a princípio, a mesma. Nesse sentido, podemos dizer que as identidades são 


\section{pro.posıções}

$e$-ISSN 1980-6248

negociadas, ou seja, "as pessoas entram e saem dos grupos de pertencimento ou aderem e afastam-se" deles, em um processo dinâmico que vai além da autodenominação; trata-se também de estratégias de contestação e expressões de transgressão (Ennes \& Marcon, 2014, p. 292). A origem socioeconômica e a profissão que Luiz seguiu ainda criança - a mesma do pai - tornam-se, nesse sentido, mais importantes no processo de invenção de si ${ }^{25}$ e de construção das vivências infantis. Segundo sua narrativa, para "pretos e pobres", como ele, não havia como dar continuidade aos estudos; por isso, logo que concluiu o curso primário, foi para a oficina de carpinteiro aprender o ofício que praticou ao longo de sua vida, deslocando-se constantemente entre várias localidades em busca de condições de trabalho para manter sua família.

Embora a obra de Zelita Gomes dedique apenas um pequeno espaço à narrativa de sua infância, é a partir do seu pertencimento socioeconômico - por vezes conjugado ao religioso, ao de gênero, ao de origem geográfica e ao profissional - que a autora faz a releitura dos acontecimentos vivenciados neste e em outros momentos de sua vida. O próprio subtítulo do livro, "uma trabalhadora rural do Jequitinhonha conta sua história", remete a essas diferentes identidades. A autora inicia a obra descrevendo suas cinco grandes vocações: trabalhar na roça; estudar (embora não tenha tido o direito de fazê-lo); escrever; ler; e, por fim, aquela que vai atuar como pano de fundo da sua narrativa - sua atuação político-religiosa a partir da criação das Comunidades Eclesiais de Base (CEBs). Assim, é possível observar sua narrativa questionadora/militante ao relembrar sua infância, enfatizando as oportunidades que lhe foram negadas em função de fazer parte de uma sociedade injusta:

Minha vida sempre foi semelhante à de tantas crianças da minha época, filhos de trabalhadores rurais do nosso querido Vale do Jequitinhonha, apelidado desrespeitosamente de Vale de lágrimas, da fome, da miséria e anteriormente foi batizado por algum político disfarçado, chamando-o Vale da Luta. Sim, porque apesar das lágrimas, da fome, da luta e da miséria, há a esperança de que um dia será esse o Vale da Paz e da justiça. (Gomes, 1997, p.15)

Ao falar de sua escolarização, a autora enfatiza, mais uma vez, os obstáculos enfrentados em consequência de seu pertencimento socioeconômico: aprendeu a ler, a escrever e a contar acompanhando seu pai, que era professor leigo, às escolas que só funcionavam em determinada época do ano. Esse aprendizado era, em suas palavras, “o

\footnotetext{
${ }^{25}$ Há uma vasta bibliografia que discute o processo de "invenção de si”" em autobiografias. Ver, por exemplo, Bruner e Weisser (1996) e a coletânea organizada por Souza e Abrahão (2006).
} 


\section{pro.posıções}

$e$-ISSN 1980-6248

http://dx.doi.org/10.1590/1980-6248-2016-0064

máximo e suficiente para as crianças da roça", porque, como os demais meninos e meninas pobres e da zona rural, foi "condenada a não ter o direito de melhorar os estudos" (Gomes, 1997, p.15).

A superação das dificuldades causadas pela pobreza é explicada, nas diferentes obras, de distintos modos. Na narrativa de Vicente, é possível identificar dois elementos aos quais ele atribui a causa da superação da vivência sofrida marcada pela extrema pobreza na infância: um deles é a caridade ou a "magnanimidade" de sua madrinha, que o acolheu como filho, mesmo sendo viúva e tendo outros quatro filhos biológicos, proporcionando uma situação financeira e afetiva equilibrada até os seus 25 anos, quando se mudou para Belo Horizonte para cursar Direito. O segundo elemento é o mérito pessoal, resultado de uma inteligência privilegiada, que ele apresenta como algo que fez com que superasse as adversidades e a subnutrição. $O$ autor enfatiza o fato de ter conquistado os lugares de destaque na carreira escolar e profissional sem muito esforço: estava sempre entre os cinco primeiros alunos do seminário, era o melhor intérprete de harmônio (órgão sem tubos), conseguiu ser aprovado em concursos públicos sem preparação prévia (escriturário do Banco do Brasil, vestibular de direito na UFMG, promotoria de Justiça) e, para a magistratura, afirma que foram necessários apenas dois meses de preparo. Na mesma direção, situa-se a narrativa de Luiz Gonzaga dos Santos (1963), que destaca dois principais elementos que foram decisivos para a superação dos obstáculos inerentes à sua origem "preta e pobre": a infância vivida em torno do trabalho para auxiliar os pais (o que não possibilitava "tempo pra molecagem") e o esforço e a "têmpora de caráter", comuns a outros conterrâneos bem-sucedidos (p. 166).

No caso de Zelita Gomes (1997), a condição de militante de movimentos sociais na idade adulta tem forte influência na construção de sua narrativa que, em contraste com os demais, não atribui a superação das adversidades e dos obstáculos vividos ao esforço e ao mérito individuais. Ela confere outro tipo de explicação aos problemas vivenciados na infância, como se pode observar no seguinte trecho do livro:

Claro que não aceito o fato de não ter tido oportunidade de estudar, seria comodismo de minha parte, pois sei que seria meu direito e que me foi renegado pela sociedade fajuta em que vivemos, na qual as vítimas são as famílias pobres, mas nem por isso baixei a cabeça para dizer amém a tudo. (p.16) 


\title{
pro.posıções
}

$e$-ISSN 1980-6248

http://dx.doi.org/10.1590/1980-6248-2016-0064

Em seu caso, o pertencimento religioso, vivenciado sobretudo em instâncias católicas vinculadas à Teologia da Libertação, é convocado para realizar uma crítica à sua condição de classe e auxiliá-la na superação das barreiras vividas:

\begin{abstract}
Sei, porém, que o valor da pessoa humana ... está ... sobretudo na sua vocação de ser gente, de ter um compromisso e um papel na sociedade, de ser cristão pois essa é a nossa primeira grande vocação à qual Deus nos chamou: existir, ser, nascer, viver, lutar, errar, acertar e, por fim, vencer! (p.16)
\end{abstract}

Desse modo, tal como nos casos analisados no tópico anterior, o engajamento do autor, ocorrido posteriormente à infância, em causas relacionadas ao pertencimento socioeconômico contribuiu para que a condição de pobre se tornasse o argumento explicativo central para os acontecimentos vividos ao longo da trajetória do sujeito. Para Zelita Gomes, como analisado aqui, é muito nítida a influência dos movimentos católicos progressistas na construção do sentido que confere à sua vida. No caso de Vicente de Souza e Luiz Gonzaga dos Santos, esse engajamento se dá em outros tipos de instância, e ajuda a compreender a opção pela origem socioeconômica como eixo de suas autobiografias. Vicente (2004) afirma que sua "dolorosa experiência infantil" orientava suas decisões como juiz nas causas que envolviam divórcio e guarda de filhos: evitava separar os irmãos, evitava separar os filhos de suas mães e não permitia guardas compartilhadas ou alternadas, "pois a criança precisa de estabilidade em suas relações familiares" (p.181). Luiz (1963), por sua vez, fundou, na década de 1930, “um subnúcleo da Ação Integralista Brasileira, o qual desenvolveu extraordinariamente e prestamos relevantes serviços à população humilde daquele lugar. Alfabetizamos diversas pessoas adultas de ambos os sexos, prestamos assistência social com remédios e tudo que estava ao nosso alcance" (p.73). Vê-se, assim, um duplo movimento nas relações que os autores estabelecem entre a infância narrada e os acontecimentos vividos na idade adulta. Por um lado, eles intencionam provocar no leitor a ideia de que a infância engendraria o engajamento do adulto em torno de causas relacionadas à pobreza vivida. Por outro, poderíamos pensar que eles selecionam exatamente episódios da infância que são condizentes com o que se tornaram na vida adulta. Aqueles acontecimentos vividos que escapam ao sentido que se quer conferir à vida narrada são, consciente ou inconscientemente, apagados pelo autor na narrativa. 


\section{pro.posıções \\ $e$-ISSN 1980-6248}

http://dx.doi.org/10.1590/1980-6248-2016-0064

\section{Considerações finais}

A análise realizada mostrou que a escrita sobre a infância é mediada por vários elementos que são, na narrativa, agregados (ou tornados inerentes) à trajetória do autor e a ela dão sentido. Embora as narrativas apresentem múltiplas "vozes" (Bakthin, 1997) indicadoras dos lugares de onde falam os autores (condições socioeconômicas, profissional, de gênero, religiosa, étnica...), é a partir de alguns pertencimentos, que se tornam os eixos por meio dos quais as narrativas são costuradas, que eles fazem a releitura de suas infâncias e trajetórias da vida.

No caso do tipo de autobiografia analisado neste trabalho, escrita por novos letrados, esses pertencimentos são acionados para explicar um dos grandes temas nelas presentes: as adversidades enfrentadas na infância. A superação desses obstáculos, por sua vez, embora também se articule a essas condições identitárias, é atribuída - e isso é particularmente forte nas autobiografias norte-americanas -, sobretudo, ao esforço e ao mérito individuais. A ênfase na meritocracia pode ser explicada pelo próprio tempo em que as autobiografias foram escritas e publicadas; a segunda metade do século XX, época de disseminação de tendências que vieram a ser, posteriormente, identificadas e agrupadas na expressão "ideologia do dom", principalmente nos Estados Unidos. Em alguns casos, por sua vez, o escritor-adulto, principalmente quando engajado em causas relacionadas a esses pertencimentos, atribui a superação à participação em movimentos sociais coletivos, como é o caso do catolicismo vinculado à Teologia da Libertação, típico da América Latina. No escopo deste artigo, não foi possível analisar, com maior profundidade, as especificidades e as semelhanças entre as condições de possibilidade de escrita entre autores dos dois países.

Além dos efeitos desses pertencimentos, o trabalho também revelou que o próprio lugar simbólico construído para si mesmo pelo escritor-adulto é fortemente influenciado, entre outros fatores, pela editora que publicou o livro, pela profissão que exercia e pelo endereçamento da obra. Esses aspectos, que não puderam ser aprofundados neste artigo, também são fundamentais no processo de reconstrução dos sentidos que ele atribui ao passado.

A autobiografia pode ser considerada, nesse sentido, uma fonte fértil para a investigação da história da infância, desde que não seja tomada em sua transparência, pois a 


\section{pro.posıções}

$e$-ISSN 1980-6248

escrita pode expressar muito mais um ato de engajamento do escritor-adulto no momento da elaboração da obra do que um suposto retrato da infância do passado.

\section{Fontes}

Bell, C. (1992). Foreword. In D. Travis, I refuse to learn to fail (pp.1-8). Chicago: Urban Research Press.

Brasil. Secretaria de Planejamento da Presidência da República. Fundação Instituto Brasileiro de Geografia e Estatística. (1982). IX Recenseamento Geral do Brasil - 1980. Censo Demográfico. Dados Gerais. Migração. Instrução. Fecundidade. Mortalidade. São Paulo. Volume I, Tomo IV, Número 19. Rio de Janeiro: IBGE.

Brazil. Ministerio da Agricultura, Industria e Commercio. Directoria Geral de Estatistica. (1920). Recenseamento do Brazil. Realizado em 1 de Setembro de 1920. Vol. IV (4a. parte). População. População do Brazil por Estados, Municipios e Districtos, segundo o gráo de instrucção, por idade, sexo e nacionalidade. Rio de Janeiro: Typografia da Estatistica.

Gomes, Z. (1997). Cofre de lembrançs: uma trabalhadora rural do Jequitinhonha conta sua história. Belo Horizonte: Canoa das Letras.

Grey, H. (1992). Introduction. In D. Travis, I refuse to learn to fail (pp.9-11). Chicago: Urban Research Press.

Jesus, C. M. de. (2007). Diário de Bitita. Sacrameto: Editora Bertolucci.

Kass, J. (2007). Foreword. In Les Brownlee, Les Brownlee: the autobiography of a pioneering AfricanAmerican journalist (pp.6-8). Oak Park, Il: Marion Street Press.

Les Brownlee (2007). Les Brownlee: the autobiography of a pioneering African-American journalist (edited by Priscila Ruth MacDougall). Oak Park, Il: Marion Street Press.

Oliveira, D. C. O. (2007). Prefácio. In C. M. de Jesus, Diário de Bitita (pp.5-14). Sacrameto: Editora Bertolucci.

Sanchis, P. (1997). Prefácio. In Z. Gomes, Cofre de lembranças: uma trabalhadora rural do Jequitinhonha conta sua história (pp.5-12). Belo Horizonte: Canoa das Letras.

Santos, L. G. (1963). Memórias de um carpinteiro. Belo Horizonte: Editora Bernardo Álvares. 


\section{pro.posıções}

$e$-ISSN 1980-6248

Souza, V. de (2004). Vá com Deus, mãe. Belo Horizonte: Imprensa Oficial do Estado de Minas Gerais.

Travis, D. (1992). I refuse to learn to fail. Chicago: Urban Research Press.

Unites States. Department of Education. National Center for Education Statistics. (1993). 120

Years of American Education: a statistical portrait (edited by Thomas D. Snyder). Washington, D.C.: National Center for Education Statistics.

\section{Referências}

Alberti, V. (1991). Literatura e autobiografia: a questão do sujeito na narrativa. Estudos Históricos, 4(1), 66-81. Recuperado em 22 de abril de 2016, de http://bibliotecadigital.fgv.br/ojs/index.php/reh/article/view/2313/1452

Barros, J. D. (2014). Histórias cruzadas: considerações sobre uma nova modalidade baseada nos procedimentos relacionais. Anos 90, 21(40), 277-310. Recuperado em 14 de março de 2016, de http://www.seer.ufrgs.br/index.php/anos90/article/view/42174/32274

Bezerra, B. G. (2006). Gêneros introdutórios em livros acadêmicos. Tese de Doutorado em Linguística, Programa de Pós-Graduação em Letras, Universidade Federal de Pernambuco.

Bakthin, M. (1997). Estética da criação verbal. São Paulo: Martins Fontes.

Bourdieu, P. (1996). A ilusão biográfica. In M. de M. Ferreira, \& J. Amado (Orgs.), Usos e abusos da História Oral (pp.183-191). Rio de Janeiro: Editora da Fundação Getúlio Vargas.

Bourdieu, P., \& Passeron, J.-C. (1964). Les héritiers. Paris: Éditions de Minuit.

Bruner, J., \& Weisser, S. (1996). A invenção do ser: a autobiografia e suas formas. In D. R. Olson, \& N. Torrance (Orgs.), Cultura escrita e oralidade (pp.141-161) São Paulo: Ática.

Certeau, M. de. (1982). A escrita da História. Rio de Janeiro: Forense Universitária.

Eco, U. (2008). Lector in fabula: a cooperação interpretativa nos textos narrativos (2a ed.). São Paulo: Perspectiva.

Ennes, M. A., \& Marcon, F. (2014). Das identidades aos processos identitários: repensando conexões entre cultura e poder. Sociologias, 16(35), 274-305. Recuperado em 16 de 


\section{pro.posıções}

$e$-ISSN 1980-6248

http://dx.doi.org/10.1590/1980-6248-2016-0064

março de 2016, de http://www.scielo.br/scielo.php?script=sci_arttext\&pid=S1517$45222014000100010 \& \operatorname{lng}=$ en\&nrm $=$ iso

Ferreira, A. B. de H. (1988). Dicionário Aurélio Básico da Lingua Portuguesa. Rio de Janeiro: Nova Fronteira.

Galvão, A. M. de O. (2006). A escrita autobiográfica na (re)construção de um percurso de inserção na cultura escrita. In Anais do VI Congresso Luso-Brasileiro de História da Educação, VI Congresso Luso-Brasileiro de História da Educação (p.2.735). Uberlândia - MG: Universidade Federal de Uberlândia, Sociedade Brasileira de História da Educação.

Gélis, J. (1993). A individualização da criança. In P. Ariès, \& R. Chartier (Org.), História da vida privada: da Renascença ao século das luz̧es (Vol.3, pp. 311-330). São Paulo: Companhia das Letras.

Gullestad, M. (2005). Infâncias imaginadas: construções do eu e da sociedade nas histórias de vida. Educação e Sociedade, 26(91), 509-534. Doi: 10.1590/S0101-73302005000200011

Kuhlmann Jr., M. (1998). Infância e educação infantil: uma abordagem histórica. Porto Alegre: Mediação.

Lejeune, P. (2014). O pacto autobiográfico: de Roussean à internet. Belo Horizonte: Editora da UFMG.

Souza, E. C. de, \& Abrahão, M. H. (Orgs.). (2006). Tempos, narrativas e ficções: a invenção de si. Porto Alegre: EDIPUCRS; Salvador: EDUNEB.

Submetida à avaliação em 23 de maio de 2016; revisado em 09 de novembro de 2016, aceito para publicação em 14 de marco de 2017. 